\title{
TONO EN EL CRIOLLO INGLES DE COSTA RICA
}

\author{
Mario Portilla Chaves
}

\begin{abstract}
The author asserts that the English-based Costa Rican Creole, also known as Limonese Creole, includes tone contrats. The article includes a synchronic description of three rules that affect the phonetic realization of tone in this variety: rising tone, falling tone and tone assimilation
\end{abstract}

\section{Introducción}

En el presente estudio se afirma que el criollo de Costa Rica es una lengua de acento tonal. Además, se parte de la consideración de que las denominadas lenguas de acento tonal (pitch-accent languages) son un tipo de lenguas tonales, al igual que lo son las denominadas lenguas tonales (tone languages) convencionales ${ }^{1}$. Por lo tanto, los suprasegmentales de altura con valor fonémico de una lengua de acento tonal serán tratados como tonos (tonemas) y no como acento.

La razón fundamental para haber interpretado esta lengua preferiblemente como una lengua tonal y no acentual es que, como se verá en detalle más adelante, existe en criollo una cierta cantidad de palabras monosilábicas (consideradas en este estudio como portadoras de un tono bajo subyacente) que pronunciadas en aislamiento presentan un nivel de prominencia distinto en comparación con el resto de las palabras monosilábicas (las cuales son consideradas con tono subyacente alto), a pesar de que todas las palabras monosilábicas, en ciertas circunstancias, puedan ser pronunciadas con un mismo patrón tonal descendente.

Desde la perspectiva del tratamiento de una lengua acentual, no podría rescatarse la diferencia existente entre una palabra fonéticamente con un tono bajo descendente y un tono alto descendente, si se considera que ambas palabras contienen un único y mismo acento.

Por otro lado, incluso dentro de una perspectiva de lengua acentual, si se considera que existen palabras carentes de acento en la lengua, aun así no se explicaría por qué estas palabras presentan, en algunos casos, un nivel de prominencia sejemante, pero no idéntico, al de las palabras que sí son portadoras de acento; es decir, que ambos grupos de palabras presenten un tono claramente descendente (bajo descendente y alto descendente, respectivamente), cuando son pronunciadas en aislamiento. 
Otra de las razones para analizar preferentemente esta lengua como tonal es el hecho de que una serie de palabras compuestas que presentan por lo menos dos niveles de prominencia culminativos idénticos (interpretados como tonos altos subyacentes) que contrastan con otros niveles de prominencia no culminativos (interpretados como tonos bajos).

Si estas palabras se analizaran desde la perspectiva de una lengua acentual, habría que reconocer que ellas son portadoras de dos niveles de prominencia culminativa, los cuales deben ser interpretados como dos acentos subyacentes. Este hecho contradice la definición tradicional, generalmente aceptada, de lo que es una lengua acentual, según la cual una palabra presenta una única sílaba portadora del acento principal. En todo caso, considerar que en estas palabras los dos niveles de prominencia culminativa reflejan un acento principal y otro secundario sería distorsionar claramente de los datos.

\section{Oposiciones tonales: $[+$ alto $]:[-$ alto $]$}

Fonológicamente, pueden distinguirse en esta lengua dos tonos de nivel: un tono alto $/ \dashv /$ y un tono bajo / $\lrcorner /$. Como ha sido mencionado anteriormente, por lo general, todas las palabras contienen por lo menos un tono alto; sin embargo, existe un reducido grupo de palabras monosilábicas que se caracterizan por poseer tono bajo.

Los siguientes son ejemplos de contrastes tonales 2 :

$\begin{array}{lll}\text { / án / } & / \dashv / & \text { mano } \\ \text { / àn / } & / \dashv / & \text { and } \\ \text { / fá:dà / } & / \dashv \dashv / \text { padre } \\ \text { / fà:dá / } & / \dashv \dashv / \text { sacerdote } \\ \text { / tíelà / } & / \dashv \dashv / \text { sastre } \\ \text { / tìelá / } & / \dashv \dashv / \text { Taylor (apellido) } \\ \text { / wélkìm / } & / \dashv \dashv / \text { welcome (n.) } \\ \text { / wèlkńm / } & / \dashv \dashv / \text { welcome (v.) }\end{array}$

Como se puede notar en los ejemplos anteriores, en palabras simples formadas de dos o más sílabas solamente una sílaba puede llevar tono alto.

\section{Realización fonética de los tonos}

Existe una regla general de descenso en la posición final de enunciado, la cual tiene una aplicación optativa para los tonos altos y obligatoria para los tonos bajos.

Según esta regla optativa de descenso, un tono fonológicamente alto / $\dashv$ / puede manifestarse fonéticamente ya sea como un tono alto [ $\neg$ ], ya sea como un tono alto descendente [ $\mathrm{V}$ ]; esto es, como un tono de contorno en el cual existe un descenso desde una altura alta hasta una altura baja. 
Por otra parte, la aplicación de esta regla, la cual en este caso tiene un carácter obligatorio, hace que un tono fonológicamente bajo / $\mathrm{f} /$ se manifieste fonéticamente como un tono bajo descendente $[\checkmark$ ]; esto es, como un tono de contorno con un descenso desde una altura baja hasta una altura extra baja. En ambos casos se trata, pues, de la aplicación de la misma regla de descenso. Esta regla puede ser representada en términos de rasgos distintivos dẹ la siguiente manera:
(1) Regla de descenso tonal
(optativa para tonos altos; obligatoria para tonos bajos)
[+ alto]
[ $\quad$ + descendente $] \quad$ I-\#\#
[- alto]

Ejemplos:

\begin{tabular}{|c|c|c|c|c|}
\hline / án / & $|+|$ & [ án ân ] & {$\left[\begin{array}{ll}-1 & \vee\end{array}\right]$} & mano \\
\hline / àn / & 131 & [ àn ] & [v] & \\
\hline / wélkìm / & $\mid \neg\lrcorner \mid$ & [ wélkńm wélkn̂m ] & [オフ フォ] & $\begin{array}{l}\text { dar la } \\
\text { bienvenida }\end{array}$ \\
\hline
\end{tabular}

Como se nota en el último ejemplo, en criollo de Costa Rica existe una regla optativa de asimilación progresiva, la cual convierte los tonos bajos subyacentes, que aparecen tras un tono alto, en tonos fonéticamente altos. La regla de asimilación de tonos bajos a tonos altos se expresa en términos de rasgos distintivos a continuación.

(2) Regla de asimilación de tonos altos (optativa)

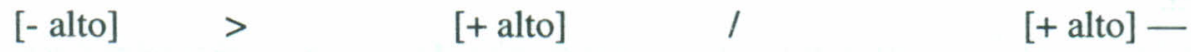

Ejemplos:

$\begin{array}{lllll}\text { / ánìmàl / } & / \dashv \dashv+/ & {[\text { ánímál ] }} & {[\dashv-1]} & \text { animal } \\ \text { / màskítà / } / \dashv \dashv-/ & {[\text { màskítá ] }} & {[\dashv-1]} & \text { mosquito } \\ \text { / àIrgétà / } & / \dashv \dashv-1 / & {[\text { àIrgétá ] }} & {[\dashv-1]} & \text { lagarto }\end{array}$

Las vocales largas están compuestas fonéticamente por dos segmentos o moras. Una vocal larga con tono bajo subyảcente presenta la primera mora con tono bajo y la segunda con un tono bajo descendente [ $-N$ ]. Por ejemplo, en la palabra / àmínìk / [ ààmíník ] [ $-N-1-$ ] armónico.

Por otra parte, una vocal larga con tono alto subyacente puede realizarse fonéticamente de dos formas diferentes. $\mathrm{O}$ bien, la primera mora presenta un tono alto y la segunda mora presenta también un tono alto [ 11 ]; por ejemplo, en la la palabra / á:mìǹ̀ / [ áámíní ] [ 1171 ] armonía. A su vez, el último tono alto puede convertirse optativamente en un tono alto descen- 
dente en posición final, según lo predice la regla 1 [ ㄱ ]; por ejemplo, en la palabra / tú: / [ túû́

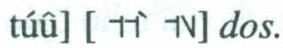

O bien, la primera mora presenta un tono bajo y la segunda mora presenta un tono ascendente; esto es, un tono de contorno que sube desde una altura media hasta una altura alta [ -11 ]. Por ejemplo, en la misma palabra citada / á:mìnì / [ àămíní ] [ 111-1] armonía.

La regla de ascenso puede presentarse en términos de rasgos distintivos de la siguiente forma.

\section{(3) Regla de ascenso tonal}

$$
\begin{aligned}
& {[+ \text { alto }] \underset{(\#=\text { linde silábico })}{>}} \\
& (+ \text { ascendente }] / \#[- \text { alto }]-\#
\end{aligned}
$$

A nivel fonológico, el autor ha interpretado que el tono que aparece en la segunda mora es el que determina el tono que se asignará a toda la vocal larga, la cual constituye una sola unidad.

Los pares mínimos citados anteriormente pueden realizarse fonéticamente de la siguiente forma en posición final de enunciado:

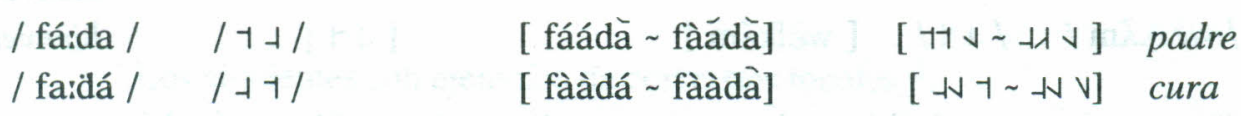

\section{Asignación de tonos en palabras compuestas}

En el criollo de Costa Rica se pueden distiguir dos clases de palabras compuestas. En una de ellas, la palabra compuesta presenta solamente un único tono alto; en la otra, la palabra compuesta puede conservar los tonos altos correspondientes a los morfemas que entran en la composición.

Ejemplos de palabras compuestas con un único tono alto:

$\begin{array}{lll}\text { / pìlísmàn / } / \dashv \dashv+/ & \text { policía } \\ \text { / sínàmàn / } & / \dashv \dashv \text { / } & \text { cantante } \\ \text { / míèlmàn / } & / \dashv \dashv / & \text { cartero } \\ \text { / sá:nstà / } & / \dashv \dashv / & \text { cantante } \\ \text { / fưtbá:l / } & / \dashv-/ & \text { fútbol }\end{array}$

Los ejemplos anteriores indican que el tono alto puede recaer tanto sobre el primer elemento del compuesto como sobre el segundo.

En la segunda clase de palabras compuestas, se conservan los tonos altos que contienen los términos que entran en la composición. Esta segunda clase se compone, por un lado, de términos formados por reduplicación morfémica y, por otro lado, de palabras que podrían más bien denominarse semicompuestos, ya que no forman una unidad fonológica compacta, sino 
que aparece un linde morfémico entre los elementos que entran en la composición. Este linde morfémico produce la aplicación de la regla de descenso descrita anteriormente, que produce sobre los tonos los efectos fonéticos mencionados.

Ejemplos de palabras compuestas con dos tonos altos son los siguientes:

\begin{tabular}{|c|c|c|}
\hline / tứpìtúpì / & $\mid \dashv-1+1$ & vagina \\
\hline / tứkùtúkù / & 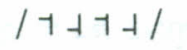 & pequeño \\
\hline / ñùs-táp / & $|-1+1|$ & techo \\
\hline / spâIdà-wéb / & $\mid-1+1-7 /$ & tela de araña \\
\hline / púsì-kját / & /-1- - - / & vagina \\
\hline
\end{tabular}

\section{Conclusión}

La interpretación del criollo de Costa Rica como una lengua tonal se ve avalada por la aparición de reglas fonéticas típicas de las lenguas tonales, tales como la asimilación, el descenso y el ascenso descritas anteriormente. Además, la descripción de estos fenómenos fonéticos que afectan a los suprasegmentales en términos de reglas tonales parece ser más adecuado que hacerlo en términos de acento.

\section{Notas}

1 Para una discusión teórica acerca de este punto véase Carter (1983).

2. Se utilizan los símbolos del Alfabeto Fonético Internacional. Cf. Portilla (1993) para una descripción de los fonemas segmentales.

3. Para una discución teórica acerca de este punto véase Carter (1983).

4. Se utilizan los símbolos del Alfabeto Fonético Internacional. Cf. Portilla (1993) para una descripción de los fonemas segmentales.

\section{Bibliografía}

Carter, H.

1983 How to be a tone language. En Carrington et al. (eds.), 1983: 90-111.

Carrington, L. et al (eds.)

1983 Studies in Caribbean Language. St. Augustine: Society for Caribbean Linguistics.

Portilla, M.

1993 Fonemas segmentales en el criollo inglés de Limón. Revista de Filología y lingüística de la Universidad de Costa Rica 19: 89-97. 